\title{
PERAN PEKERJA SOSIAL DALAM REHABILITASI SOSIAL KEPADA ORANG DENGAN DISABILITAS MENTAL EKS PSIKOTIK DI PANTI SOSIAL BINA LARAS “PHALA MARTHA” SUKABUMI
}

\author{
Oleh: \\ Ruswanto, Moch. Zaenudin, \& Hery Wibowo \\ Email: ruswantotjl@gmail.com
}

\begin{abstract}
ABSTRAK Orang dengan disabilitas mental eks psikotik adalah seseorang yang mempunyai kelainan mental atau tingkah laku karena pernah mengalami sakit jiwa yang oleh karenanya merupakan rintangan atau hambatan baginya untuk melakukan pencarian nafkah atau kegiatan kemasyarakatan dan dengan faktor penyebab utama adalah adanya kerusakan/tidak berfungsinya salah satu atau lebih Sistem Syaraf Pusat (SSP) yang terjadi sejak lahir, penyakit, kecelakaan dan juga karena keturunan. Oleh sebab itu, orang dengan disabilitas mental eks psikotik membutuhkan suatu bentuk pelayanan sosial dalam rangka mengembalikan fungsi sosialnya. Pelayanan sosial bagi penderita gangguan jiwa Psikotik selama ini dilaksanakan melalui sistem dalam panti, seperti Panti Sosial Bina Laras (PSBL) "Phala Martha" Sukabumi. PSBL Phala Martha merupakan Unit Pelaksana Teknis (UPT) di lingkungan Kementerian Sosial Republik Indonesia yang berada di bawah dan bertanggung jawab langsung kepada Direktur Jenderal Rehabilitasi Sosial, sehari-hari secara fungsional dibina oleh para Direktur terkait sesuai dengan bidang tugasnya. PSBL Phala Martha mempunyai tugas melaksanakan pelayanan dan rehabilitasi sosial yang bersifat kuratif, rehabilitatif, promotif dalam bentuk bimbingan fisik, mental, sosial, pelatihan keterampilan, resosialisasi serta bimbingan lanjut kepada orang dengan disabilitas mental eks psikotik agar mampu mandiri dan berperan aktif dalam kehidupan bermasyarakat serta pengkajian dan penyiapan standar pelayanan serta pemberian informasi dan rujukan. Subyek dalam penelitian ini adalah pekerja sosial yang bekerja di lingkungan PSBL Phala Martha. Dalam penelitian ini pendekatan yang digunakan adalah pendekatan kualitatif dengan metode penelitian deskriptif
\end{abstract}

Kata kunci : Orang dengan disabilitas mental eks psikotik, rehabilitasi sosial, pekerja sosial

ABSTRACT People with mental disabilities ex psychotic is someone who has a mental or behavioral disorder due to ever experience a mental illness which is therefore an obstacle or obstruction for him to do livelihood or community activities and the main factor is the damage/malfunction of one or more Central Nervous System (CNS) that occurs from birth, disease, accidents and also because of heredity. Therefore, people with mental disabilities psychotic ex require some form of social services in order to restore its social function. Social services for people with mental disorders Psychotic during implemented through the system in a home, such as Social Institution Bina Laras (PSBL) "Phala Martha" Sukabumi. PSBL "Phala Martha" is a Technical Implementation Unit (UPT) in the Ministry of Social Affairs of the Republic of Indonesia which is under and responsible directly to the Director General of Social Rehabilitation, daily functionally related fostered by the Directors in their respective sectors. PSBL Phala Martha has the tasks of social services and rehabilitation that are curative, rehabilitative, promotion guidance in the form of physical, mental, social, vocational training, social reintegration and further guidance to people with mental disabilities ex psychotic to be able to independently and actively participate in social life as well assessment and preparation of 
service standards as well as providing information and referrals. Subjects in this study were social workers who work in environments PSBL Phala Martha. In this research approach used is a qualitative approach with descriptive research method.

Key Word: People with mental disabilities ex psychotic, social rehabilitation, social worker

\section{PENDAHULUAN}

Mengingat semakin pesatnya usaha pembangunan, modernisasi dan idustrialisasi yang berakibatkan kompleksnya masyarakat, maka banyak muncul masalah-masalah sosial dan gangguan/disorder mental di kota-kota besar. Makin banyaklah warga masyarakat yang tidak mampu melakukan penyesuaian diri dengan cepat terhadap macam-macam perubahan sosial. Mereka itu mengalami banyak frustasi, konflik-konflik eksternal dan internal, ketegangan batin dan menderita gangguan mental.

Individu-individu yang tidak mampu melakukan penyesuaian itu selalu merasa tidak nyaman dalam bertindak karena takut berbenturan dengan norma-norma dan kebiasaan sosial. Mereka selalu mengalami banyak ketegangan dan tekanan batin, disebabkan oleh sanksi batin sendiri ataupun oleh sanksi-sanksi sosial. Tuntutan sosial dari lingkungan sosial dan proses modernisasi menjadi semakin banyak dan berat. Misalnya pendidikan harus menjadi semakin lama, jika orang mau mendapatkan pekerjaan yang layak. Rumah dan mobil harus menjadi semakin mewah, kalau mau digolongkan dalam kelompok elit, dan seterusnya. Jika gangguangangguan emosional dan ketegangan batin itu berlangsung secara terus-menerus, menjadi kronis dalam waktu yang cukup panjang, maka muncullah kekalutan-kekalutan mental.

Salah satu bentuk dari kekalutan mental yang ada adalah orang yang mengalami gangguan jiwa psikotik. Psikosis adalah suatu gangguan jiwa dengan kehilangan rasa kenyataan (sense of reality). Kelainan seperti ini dapat diketahui berdasarkan gangguan-gangguan pada perasaan, pikiran, kemauan, dan motorik, sehingga perilaku penderita tidak sesuai lagi dengan kenyataan. Perilaku penderita Psikosis tidak dapat di mengerti oleh orang normal, sehingga orang awam menyebut penderita sebagai orang gila (W.F.Maramis, 2012).

Menurut data dari WHO masalah gangguan kesehatan jiwa di seluruh dunia memang sudah menjadi masalah yang sangat serius. Pada tahun 2001 kira-kira 450 juta orang dewasa dari populasi dunia mengalami gangguan jiwa Psikotik. Bahkan setiap orang mempunyai kemungkinan pernah mengalami episode Psikosis pada beberapa tahap dalam kehidupannya. Data AmericanPsychiatric Association (APA) tahun 2000 menyebutkan di Amerika Serikat satu dari seratus orang penduduk beresiko untuk menderita Psikotik (Suliswati, 2005).

Sementara untuk kasus gangguan jiwa penderita Psikotik, jumlah penderita Psikotik di Indonesia adalah 3 sampai 5 per 1000 penduduk. Mayoritas penderita berada di kota besar. Ini terkait dengan tingginya stres yang muncul di daerah perkotaan. Berdasarkan laporan hasil Riset Kesehatan Dasar (Riskesdas) tahun 2007 yang dilakukan oleh Departemen Kesehatan Republik Indonesia, memperlihatkan prevalensi nasional penderita gangguan jiwa Psikotik 0,46\% atau sekitar 1 juta jiwa. Jika jumlah penduduk Indonesia diperkirakan 250 juta, maka penderita gangguan jiwa Psikosis yang harus ditemukan adalah (3-5/1000x250 jt) 750.000 sampai 1.250.000 penderita. Dengan angka ini dapat dikatakan penderita Psikotik termasuk ke dalam kelompok minoritas yang rentan akan diskriminasi.

Keadaan di Indonesia orang yang mengalami gangguan jiwa Psikotik diperlakukan secara tidak pantas karena masyarakat melakukan diskriminasi terhadap penderita gangguan 
jiwa. Penyakit jiwa, sampai saat ini masih dianggap sebagai penyakit yang memalukan,menjadi aib bagi si penderita dan keluarganya. Masyarakat kita menyebut penyakit jiwa padatingkat yang paling kronis, seperti hilang ingatan, dengan sebutan yang sebenarnya sangat kasar seperti: sinting, otak miring atau gila serta sebutan-sebutan kasar lainnya. Lihat saja kenyataan, orang-orang mungkin termasuk kita sendiri jika melihat atau berpapasandengan orang yang sakit jiwa, dengan spontan akan menertawakan, mencemooh, memaki-maki bahkan melemparinya. Menganggap orang yang sakit jiwa sebagai makhluk kotor, rendah danhina, bahkan mungkin dianggap lebih hina dari hewan. Bahkan ada stigma di masyarakat bahwa orang yang mengalami gangguan jiwa Psikotik cenderung berbahaya bagi masyarakat sekitar. Mereka sering melakukan tindakan kekerasan terhadap lingkungan sekitar yang dapat merepotkan ataupun membahayakan bagi masyarakat sehingga tidak jarang mereka dipasung.

Hal ini tentu sangat memprihatinkan, para penderita Psikotik yang seharusnya diperlakukan dengan baik dan mendapatkan pelayanan justru mendapatkan perlakuan yang diskriminasi dari masyarakat, bahkan mungkin oleh keluarganya sendiri. Hal ini sebagai konsekuensi dari meningkatnya para penderita Psikotik setiap tahunnya maka pelayanan terhadap para penderita Psikotik harus menjadi perhatian penuh berbagai pihak, terutama yang dilakukan oleh keluarga dan masyarakat yang sesuai dengan usaha-usaha kesejahteraan sosial yang merupakan kewajiban bagi setiap warga negara.

Pelayanan sosial bagi penderita gangguan jiwa Psikotik selama ini dilaksanakan melalui sistem dalam panti, seperti Panti Sosial Bina Laras (PSBL) "Phala Martha" Sukabumi. PSBL Phala Martha merupakan Unit Pelaksana Teknis (UPT) di lingkungan Kementerian Sosial Republik Indonesia yang berada di bawah dan bertanggung jawab langsung kepada Direktur Jenderal Rehabilitasi Sosial, sehari-hari secara fungsional dibina oleh para Direktur terkait sesuai dengan bidang tugasnya.

PSBL Phala Martha mempunyai tugas melaksanakan pelayanan dan rehabilitasi sosial yang bersifat kuratif, rehabilitatif, promotif dalam bentuk bimbingan fisik, mental, sosial, pelatihan keterampilan, resosialisasi serta bimbingan lanjut kepada orang dengan kecacatan mental eks psikotik agar mampu mandiri dan berperan aktif dalam kehidupan bermasyarakat serta pengkajian dan penyiapan standar pelayanan serta pemberian informasi dan rujukan.Pelayanan rehabilitasi sosial kepada orang dengan kecacatan mental eks psikotik yang dilaksanakan di Panti Sosial Bina Laras (PSBL) "Phala Martha" Sukabumi menggunakan metode : "Family therapy." PSBL "Phala Martha" Sukabumi merupakan keluarga pengganti sementara bagi orang dengan kecacatan mental eks psikotik untuk menjalani proses rehabilitasi sosial dengan tetap memberikan penguatan kepada keluarga intinya agar klien dan keluarga dapat kembali menjalani kehidupan secara baik dan wajar di tengah-tengah masyarakat. Tugas Pekeja Sosial sebagai manajer kasus klien dalam rehabilitasi sosial antara lain melaksanakan ; assesment, perencanaan, menghubungkan/rujukan, advokasi kasus, monitoring dan konseling.

\section{TINJAUAN PUSTAKA}

\section{Manajemen Kasus Dalam Pekerjaan Sosial}

Seringkali seseorang mengalami suatu permasalahan yang sesungguhnya membahayakan jiwa maupun raga. Namun mereka tidak tahu cara keluar dari masalahnya tersebut atau tidak berani melakukakannya, sehingga kondisi demikian membutuhkan pertolongan orang lain untuk membantu mengatasi permasalahannya.

Keterampilan manajemen kasus (case management) merupakan suatu metoda pendekatan pekerjaan sosial yang bertujuan memberikan pelayanan terhadap orang dalam situasi dan kondisi meminta atau mencari pertolongan. Pelayanan yang diberikan 
diharapkan dapat menjamin orang yang mempunyai masalah akan memperoleh semua pelayanan yang dibutuhkannya secara cepat dan tepat. Oleh karena itu, seorang manajer kasus harus mempelajari dan mampu mempertimbangkan masalah dan kebutuhan klien berdasarkan hasil asesmen yang dibuat oleh assesor.

Dengan beragamnya jenis masalah yang dihadapi klien, maka seorang manajer kasus dituntut melaksanakan fungsi-fungsinya guna memaksimalkan pertolongan yang akan diberikan. Salah satu fungsi manajemen kasus yang tidak dapat dilaksanakan sendirian adalah fungsi koordinasi, karena dalam pelaksanaannya akan selalu berhubungan dengan orang lain untuk mengakses sumbersumber yang tersedia di masyarakat guna memaksimalkan pertolongan yang akan diberikan. Rose,1992 dalam Compton, 1999, bahwa: "untuk beberapa hal, manajemen kasus berarti membantu klien untuk mengakses sumber-sumber yaitu dengan mengatur sumber-sumber dari masyarakat"

Lauber: 1992 dan More:1990 dalam Comton :1999 bahwa: "salah satu fungsi dari pekerjaan sosial adalah koordinasi dukungan sosial formal". Begitu juga Robert L. Balker (1982: 20) bahwa: Case management is a procedure to coordinate all the helping activities on be help of client or group of clients"(kegiatan dalam manajemen kasus merupakan kegiatan yang memiliki prosedur untuk mengkoordinasi seluruh aktivitas pertolongan yang diberikan kepada klien secara perorangan maupun kelompok).

Koordinasi seyogyanya dilakukan secara professional oleh teamwork yaitu antara pekerja sosial satu dengan pekerja sosial dan atau dengan profesi lain sehingga upaya pelayannya dapat ditingkatan sesuai kebutuhan klien. Selaku teamwork, maka ada beberapa kaidah yang harus dilaksanakan oleh pekerja sosial, antara lain:

1) Tumbuhkan rasa perhatian terhadap klien.

2) Ciptakan kepecayaan antar team.
3) Tanggung jawab terhadap persoalan yang dihadapi klien.

4) Terbuka.

5) Fokus pada tujuan pemecahan masalah.

\section{Rehabilitasi Sosial}

Rehabilitasi sosial yang dikutip oleh Zaenudin (1994) dari pendapat L.E. Hinsie dan Canbell, bahwa rehabilitasi sosial adalah segala tindakan fisik, penyesuaian psikologis dan penyesuaian diri secara maksimal untuk mempersiapkan klien secara fisik, mental, sosial, keterampilan bagi kehidupan sesuai dengan kemampuan. Dimana pada prosesnya diarahkan sebagai berikut :

1. Mencapai perbaikan penyesuain klien sebesar-besarnya

2. Kesempatan keterampilan sehingga dapat bekerja dengan kapasitas maksimal

3. Penyesuaian diri dalam lingkungan perorangan dan sosial secara memuaskan sehingga dapat berfungsi sebagai anggota masyarakat

Sedangkan menurut The National Council On Rehabilitaion dalam memberikan definisi sebagai berikut : Rehabilitation as restoration of the handicapped to the fullest, mental, social vakational and economic use fullness of which they are capable". (dari pengertian tersebut upaya rehabilitasi tidak hanya diarahkan pada suatu jenis hambatan saja, akan tetapi untuk berbagai jenis hambatan baik fisik, mental, sosial, ekonomi dan latihan keterampilan. (1942:20).

Program sasaran rehabilitasi merupakan suatu usaha pelayanan kesejahteraan sosial yang kegiatannya meliputi bimbingan fisik, mental, sosial, ekonomi, dan keterampilan. Pembinaan tersebut diarahkan pada perubahan sikap serta penyembuhan dari berbagai permasalahan yang dialami.

Tujuan Rehabilitasi Sosial

Tujuan Rehabilitasi Sosial adalah untuk memulihkan kembali rasa harga diri, percaya 
diri, kesadaran serta tanggung jawab terhadap masa depan diri, keluarga maupun masyarakat atau lingkungan sosialnya, dan memulihkan kembali keamanan dan kemampuan agar dapat melaksanakan fungsi sosialnya secara wajar untuk mencapai tujuan tersebut, maka kegiatan yang dilakukan adalah sebagai berikut :

1. Rehabilitasi diberikan melalui bimbingan sosial dan pembinaan mental, bimbingan keterampilan. Bimbingan sosial yang diberikan baik secara individu maupun kelompok.

2. Usaha rehabilitasi ini untuk meningkatkan kesadaran individu terhadap fungsi sosialnya dan menggali potensi positif seperti bakat, minat, dan hobi, sehingga timbul kesadaran akan harga diri serta tanggung sosial secara mantap.

Sedangkan definisi rehabilitasi dalam ensiklopedia mini pekerjaan sosial karangan Hudri adalah (1994:102) :

"Upaya memulihkan kapasitas agar kembali dalam keadaan sehat dan dapat dimanfaatkan atau dipulihkan kepada suatu kondisi yang memuaskan. Pekerjaan sosial menggunakan istilah ini dalam konteks membantu orangyang telah terganggu kapasitasnya, karena luka, sakit atau tidak dapat berfungsi. Proses rehabilitasi ini digunakan di rumah-rumah sakit, badan-badan atau panti sosial, klinik sekolah-sekolah, lembaga pemasyarakatan dan sebagainya".

Dengan demikian rehabilitasi merupakan suatu usaha untuk mengembalikan kemampuan fisik, mental dan sosial seseorang sehingga dapat menjalankan fungsi sosial kembali mampu mengatasi masalah yang di hadapi. Dalam program rehabilitasi perhatian dititik beratkan pada pemantapan dan pengembangan kepribadiannya agar dapat dikembalikan pada masyarakat.

\section{Orang dengan Disabilitas Mental Eks Psikotik}

Orang dengan disabilitas mental eks psikotik adalah seseorang yang mempunyai kelainan mental atau tingkah laku karena pernah mengalami sakit jiwa yang oleh karenanya merupakan rintangan atau hambatan baginya untuk melakukan pencarian nafkah atau kegiatan kemasyarakatan dan dengan faktor penyebab utama adalah adanya kerusakan/tidak berfungsinya salah satu atau lebih Sistim Syaraf Pusat (SSP) yang terjadi sejak lahir, penyakit, kecelakaan dan juga karena keturunan

Sebab-sebab Disabilitas Mental eks Psikotik

1. Tekanan-tekanan kehidupan emosional dan konflik batin.

2. Kekecewaan (frustasi) yang tidak pernah mendapat penyelesaian.

3. Hambatan-hambatan yang terjadi pada masa perkembangan.

4. Kecelakaan yang menimbulkan kerusakan pada jaringan otak.

5. Sosial budaya, yaitu yang menyangkut ketidak mampuan menyesuaikan diri dengan adanya perubahan-perubahan lingkungan hidup.

Ciri-ciri Orang dengan Disabilitas Mental Eks Psikotik:

- Mengalami hambatan fisik mobilitas dalam kegiatan sehari-hari.

- Memiliki hambatan dan gangguan dalam keterampilan kerja produktif.

- Memiliki hambatan/kecanggungan mental psikologis yang menimbulkan rasa rendah diri, lemah kemauan dan kerja serta rasa tanggung jawab terhadap masa depan sendiri.

- Memiliki hambatan dalam melaksanakan fungsi sosial secara wajar.

Jenis-Jenis Orang dengan Disabilitas Mental Eks Psikotik

1. Psikotik Organik 
a. Yaitu jenis psikotik yang faktor penyebabnya ialah adanya gangguan pada pusat susunan urat syaraf.

b. Psikotik yang disebabkan oleh kondisi fisik termasuk gangguan endoktrin, gangguan metabolisme, keadaan psikotik karena adanya infeksi tubuh, intoksikasi obat, setelah pembedahan dan lain-lain.

Gangguan tersebut meliputi :

- Gangguan orientasi

- Gangguan daya ingatan

- Gangguan fungsi berpikir.

\section{Psikotik Fungsional (Psikogenik)}

Psikotik yang tidak disebabkan oleh kerusakan organik tetapi gangguan terutama terdapat aspek-aspek kepribadian atau fungsi dari kepribadian, serta yang bersifat psikogenik ini termasuk :

- Skizoprenia kepribadian)

(perpecahan

- Psikotik paranoid (Selalu curiga pada orang lain) Psikotik afektif.

- Psikotik reaktif.

Peran Pekerja Sosial dalam Panti Sosial Bina Laras "Phala Martha"

Pelayanan rehabilitasi sosial kepada orang dengan disabilitas mental eks psikotik yang dilaksanakan di Panti Sosial Bina Laras (PSBL) "Phala Martha" Sukabumi menggunakan metode : "Family therapy." PSBL "Phala Martha" Sukabumi merupakan keluarga pengganti sementara bagi orang dengan disabilitas mental eks psikotik untuk menjalani proses rehabilitasi sosial dengan tetap memberikan penguatan kepada keluarga intinya agar klien dan keluarga dapat kembali menjalani kehidupan secara baik dan wajar di tengah-tengah masyarakat.
Tugas Pekeja Sosial sebagai manajer kasus klien dalam rehabilitasi sosial antara lain melaksanakan ; asesmen, perencanaan, menghubungkan/rujukan, advokasi kasus, monitoring dan konseling.

- Pekerja Sosial melaksanakan asesmen terhadap aspek kebutuhan, kapasitas dan dukungan biopsikososial klien.

- Pekerja Sosial melaksanakan perencanaan dengan tindakan dan tujuan yang kongkrit serta koordinasi layanan.

- Pekerja Sosial melaksanakan rujukan dengan cara mengkaitkan klien dan keluarga dengan sistem layanan.

- Pekerja Sosial melaksanakan advokasi kasus membantu klien dan keluarga memperoleh akses layanan untuk memenuhi kebutuhannya dan pemberdayaan keluarga.

- Pekerja Sosial melaksanakan pemantauan secara teratur terhadap klien dan keluarga serta penyedia layanan agar layanan sesuai dengan kebutuhan, tepat waktu pada keluarga yang rentan atau mengalami resiko dan masalah.

Kegiatan pelayanan rehabilitasi sosial yang diberikan kepada klien meliputi ; bimbingan fisik, mental sosial dan vokasional.

- Bimbingan fisik meliputi ; pemenuhan kebutuhan dasar, pemeriksaan kesehatan fisik, olahraga dan seni budaya.

- $\quad$ Bimbingan mental meliputi ; pemeriksaan kesehatan jiwa , pengetahuan dasar perawatan kesehatan jiwa, dan bimbingan agama.

- Bimbingan sosial meliputi ; bimbingan sosial individu dan kelompok.

- Bimbingan vokasional meliputi ; keterampilan kerajinan tangan, menjahit, 
olahan pangan, pertanian, perikanan, batako/paving block.

\section{DAFTAR PUSTAKA}

\section{Buku :}

Hudri. 1994. Ensiklopedia Mini (432 istilah) Pekerja Sosial. Bandung.

Pincus, Allen and Anne Minahan. 1974. Social Work Practice : Model ND Method. Itasca Illinois : Peacock Publishers, Inc.

Barker, Robert L. 1983. The Social Work Dictionary $3^{\text {rd }}$ edition.
Moleong. Lexy, J. 2004. Metodelogi Penelitian Kualitatif. Bandung: PT. Remaja Rosda Karya.

Website :

https://www.academia.edu/5924220/Word_ga ngguan_psikotik diakses pada tanggal 10 Maret 2015

http://phalamartha.depsos.go.id/modules.php? $\underline{\text { name }}=$ Content $\& \mathrm{pa}=$ showpage $\&$ pid $=$ 16 diakses pada tanggal 20 Maret 2015 